\section{Visualizing the Historical and Contemporary Differences in Mortality Between the United States and Canada Using Lexis Diagrams}

\section{Dear Editor:}

To better appreciate mortality differences between two countries, it is useful to compare sex-specific rates across both age groups and time. Lexis diagrams facilitate this, ${ }^{1}$ but have remained underutilized. Combining two Lexis diagrams allows us to effectively visualize changes in comparative mortality ratios between two countries over time, between years, and within cohorts. To highlight this, the example of comparing the ratio of mortality rates in the United States (US) and Canada is presented.

Mortality data were gathered from the "Human Mortality Database", ${ }^{2}$ which provides both birth and death counts for 37 countries. Mortality rates were collected for individual (1933-2007) years and ages (0-100). This was input into Lexis software to produce the figures shown here illustrating the variation in mortality ratios between the two countries. ${ }^{3}$ Both the data and software are freely available for any researcher to be able to replicate this study.

Figures 1 and 2 show the ratio of US and Canadian mortality rates, split by sex. Canada has consistently had lower rates of mortality for those aged 20 to 60 over the time period shown. This difference appears to have strengthened since the 1980s, around the time of the introduction of the Canada Health Act, which prohibited the use of fees and extra billing by doctors. ${ }^{4}$ While Canada has generally benefited from suffering lower mortality below the age of 60 than the US, until the 1980s mortality rates were higher for those in Canada under the age of 20 compared to the same age group in the US. The gradual reversal in this pattern started from around the period of the introduction of the current health care system, leading to a widening gap which has been recognized in infants since 1996, but not for the wider age group or time period. ${ }^{5}$

In the US, mortality has generally been lower than in Canada at older ages, although this advantage has also reduced in recent years. We do not plot values above the age of 100 due to the low numbers involved overall, but especially due to there being few Canadians reported as living past 100 , unlike in the more populous US. While Canada has traditionally enjoyed lower mortality rates than the US, it does not experience much extreme longevity. Inequality in mortality in the US, with more people dying young and more living to be very old, continues to be far higher than in Canada. However, since the mid-1990s (especially with females), the relative advantages for older US citizens have been diminishing and the disadvantages for younger adults have been growing.

There have been many studies that have tried to understand why mortality rates vary as they do between Canada and the US. These often concentrate on particular medical interventions. ${ }^{6}$ Few take a more historical and societal overview. Lexis diagrams visualize these changing patterns and trends efficiently, improving our understanding of the processes that have led to these inequalities.

\section{Mark A. Green, MSc, Danny Dorling, PhD}

Department of Geography, The University of Sheffield, Sheffield, UK

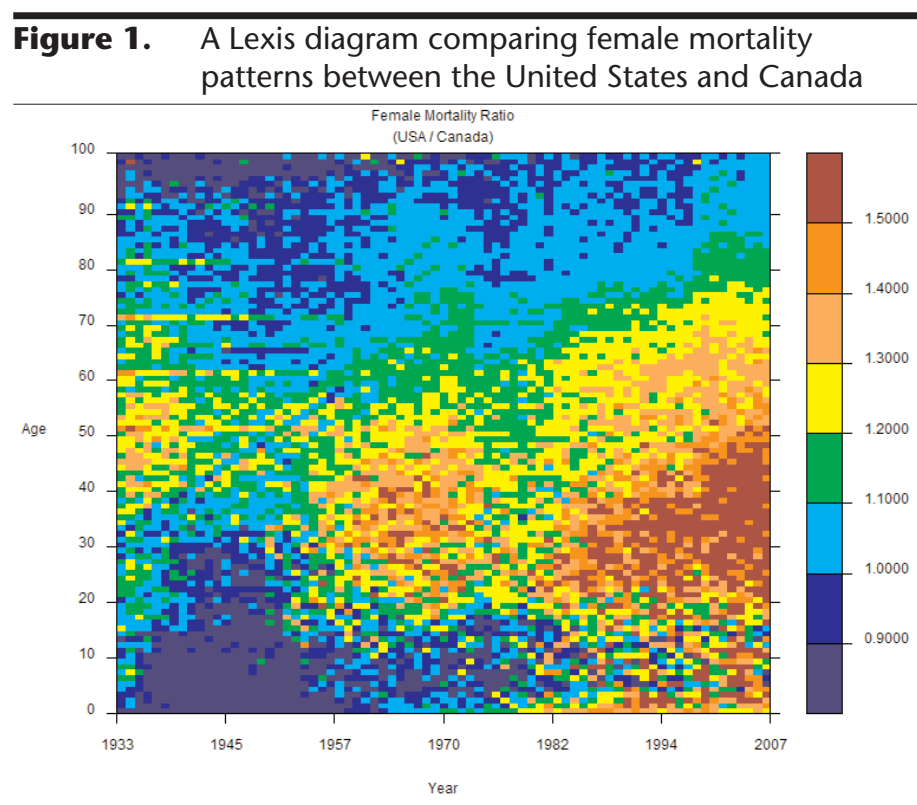

Key: The diagram presents a ratio of mortality rates (the mortality rate of the US divided by the Canadian mortality rate), with each pixel representing a specific single year and single year-of-age-group. A value greater than one indicates that the female mortality rate in America is higher than in Canada for that specific age and time period, and vice versa. For example, a value of 1.4 reveals that in America, the mortality rate is $40 \%$ higher than for the equivalent year and age group of people living at that time in Canada.

Figure 2. A Lexis diagram comparing male mortality patterns between the United States and Canada



Note: See key to Figure 1 for details on interpretation.

\section{REFERENCES}

1. Lexis W. Einleitung in die Theorie der Bevölkerungsstatistik. Strassburg: Karl J. Trübner, 1875

2. Human Mortality Database. University of California, Berkeley (USA), and Max Planck Institute for Demographic Research (Germany). Available at: www.mortality.org or www.humanmortality.de (Accessed May 21, 2012).

3. Andreev KF. Evolution of the Danish Population from 1835 to 2000. Available at: http://www.demogr.mpg.de/books/odense/9/cd/default.htm (Accessed May 25, 2012).

4. Iglehart JK. Revisiting the Canadian health care system. N Engl J Med 2000;342(26):2007-12.

5. Ananth CV, Liu S, Joseph KS, Kramer MS, for the Fetal and Infant Health Study Group of the Canadian Perinatal Surveillance System. A comparison of foetal and infant mortality in the United States and Canada. Int J Epidemiol 2009;38(2):480-89.

6. Guyatt GH, Devereaux PJ, Lexchin J, Stone SB, Yalnizyan A, Himmelstein D, et al. A systematic review of studies comparing health outcomes in Canada and the United States. Open Med 2007;1(1):27-36. 